\title{
Cutaneous involvement as a rare first sign of systemic mantle cell lymphoma: A case report and review of the literature
}

\author{
IGOR HRGOVIC $^{1 *}$, SYLVIA HARTMANN ${ }^{2 *}$, BJÖRN STEFFEN ${ }^{3}$, THOMAS VOGL ${ }^{4}$, \\ ROLAND KAUFMANN $^{1}$ and MARKUS MEISSNER ${ }^{1}$
}

\begin{abstract}
${ }^{1}$ Department of Dermatology, Venereology and Allergology; ${ }^{2}$ Institute of Pathology; ${ }^{3}$ Division of Hematology/Oncology, Department of Internal Medicine; ${ }^{4}$ Institute for Diagnostic and Interventional Radiology, Johann Wolfgang Goethe University Hospital of Frankfurt, D-60590 Frankfurt am Main, Germany
\end{abstract}

Received October 16, 2015; Accepted February 9, 2016

DOI: $10.3892 /$ mco.2016.792

\begin{abstract}
Mantle cell lymphoma (MCL) is a unique type of B-cell non-Hodgkin's lymphoma, which very rarely exhibits skin involvement. We herein describe the case of a 55-year-old woman, who initially presented with a nodular mass of the right infraorbital region. On histological analysis of the subcutaneous tissue, a diffuse neoplastic cell infiltration was identified, composed of medium-sized lymphoid cells with irregular nuclei, which was diagnosed as MCL. The tumor cells were positive for CD5, CD20, CD79a, cyclin D1 and sex-determining region Y-box 11, but negative for CD10 and CD23. Our patient received six cycles of R-CHOP chemotherapy and intrathecal methotrexate as central nervous system prophylaxis. However, the patient relapsed 1 year later and was treated with two cycles of R-DHAP and one cycle of intrathecal methotrexate. After achieving partial remission, the patient was consolidated with peripheral blood stem cell transplantation using the BEAM conditioning regime. While prior case studies suggest that skin invasion by MCL is associated with a poor prognosis, our patient remains alive almost 4 years after the initial presentation. Skin involvement as a first sign of systemic MCL is very rare and must be considered.
\end{abstract}

Correspondence to: Dr Markus Meissner, Department of Dermatology, Venereology and Allergology, Johann Wolfgang Goethe University Hospital of Frankfurt, Theodor-Stern-Kai 7, D-60590 Frankfurt am Main, Germany

E-mail: markus.meissner@kgu.de

${ }^{*}$ Contributed equally

Abbreviations: MCL, mantle cell lymphoma; NHL, non-Hodgkin's lymphoma; PBSC, peripheral blood stem cell transplant; CR, complete remission; OS, overall survival; CNS, central nervous system

Key words: mantle cell lymphoma, non-Hodgkin's lymphoma, sex-determining region Y-box 11, skin involvement, peripheral blood stem cell transplant, retuximab

\section{Introduction}

Mantle cell lymphoma (MCL) is an aggressive subtype of B-cell non-Hodgkin's lymphoma (NHL) that usually involves lymph nodes and extranodal organs, such as the bone marrow, spleen and gastrointestinal tract. MCL is characterized by a subset of $\mathrm{CD}^{-}, \mathrm{CD} 20^{-}, \mathrm{CD} 79 \mathrm{a}^{-}$and cyclin $\mathrm{D1}^{+}$tumor cells (1). Skin involvement is very rare in MCL; in these cases, cutaneous lesions may represent the first symptom of the disease (2). In the present report, a rare case of MCL with cutaneous involvement as the first manifestation of the disease is presented, along with a detailed 4-year follow up, and the previously reported cases of MCL with cutaneous manifestations are reviewed.

\section{Case report}

A 55-year-old Caucasian woman was referred to our clinic in July, 2008 for investigation of a large subcutaneous nodule $(\sim 4 \mathrm{~cm})$ in the right infraorbital region. The patient reported that the tumor had increased in size over the previous 12 months (Fig. 1). The patient also described experiencing other symptoms, including fever, night sweats and weight loss. A physical examination revealed no other pathological findings and hypothyroidism was noted as a pre-existing condition.

Initial blood tests revealed a moderate decrease in the white blood cell count (3.86/nl), with an inverted cellular type (neutrophils: $74.4 \%$; and lymphocytes: $14.6 \%$ ), mildly elevated lactate dehydrogenase $(233 \mathrm{U} / 1)$ and $\beta 2$-microglobulin $(2.9 \mathrm{mg} / \mathrm{l})$ levels, with a normal hemoglobin concentration $(12.6 \mathrm{~g} / \mathrm{dl})$ and platelet count $(182 / \mathrm{nl})$. The hepatic and renal functions were normal.

Excision of the nodular lesion was performed. Histological examination revealed a deep subcutaneous infiltration by a nodular mass of medium-sized lymphoid cells with irregular nuclei. Immunohistochemical analysis revealed a population of lymphoblasts that were strongly positive for CD5, CD20, CD79a, cyclin D1, sex-determining region Y-box 11 (SOX11) and Ki67 (Fig. 2), but negative for CD10 and CD23.

Contrast-enhanced computed tomography (CT) of the neck and thorax revealed a $3.2 \times 5.5 \times 3.6-\mathrm{cm}$ hyperdense enhancing mass in the epipharynx, involving the left side of the tonsillar region/bed. Several enlarged cervical and 


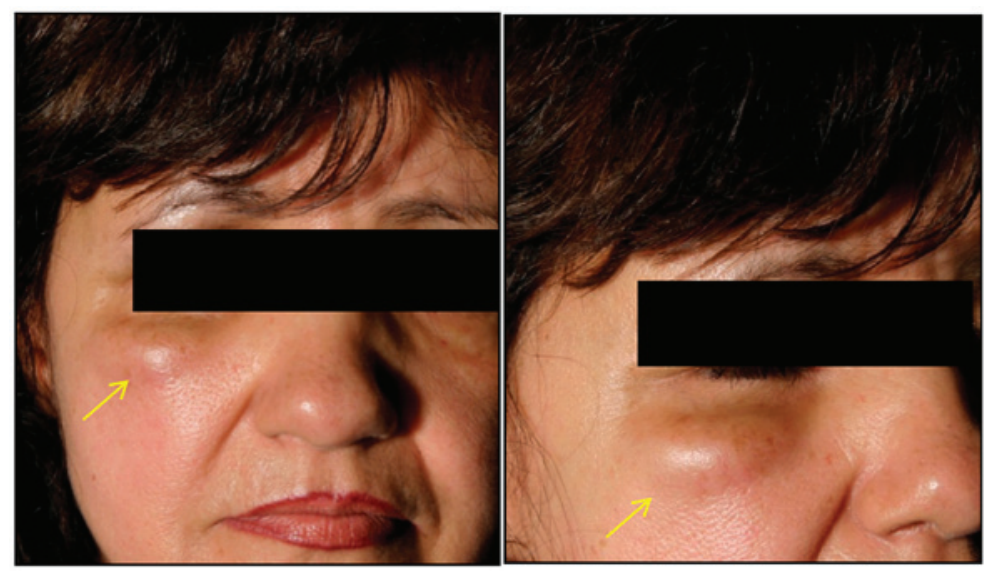

Figure 1. Subcutaneous nodule in the right infraorbital region (arrows).
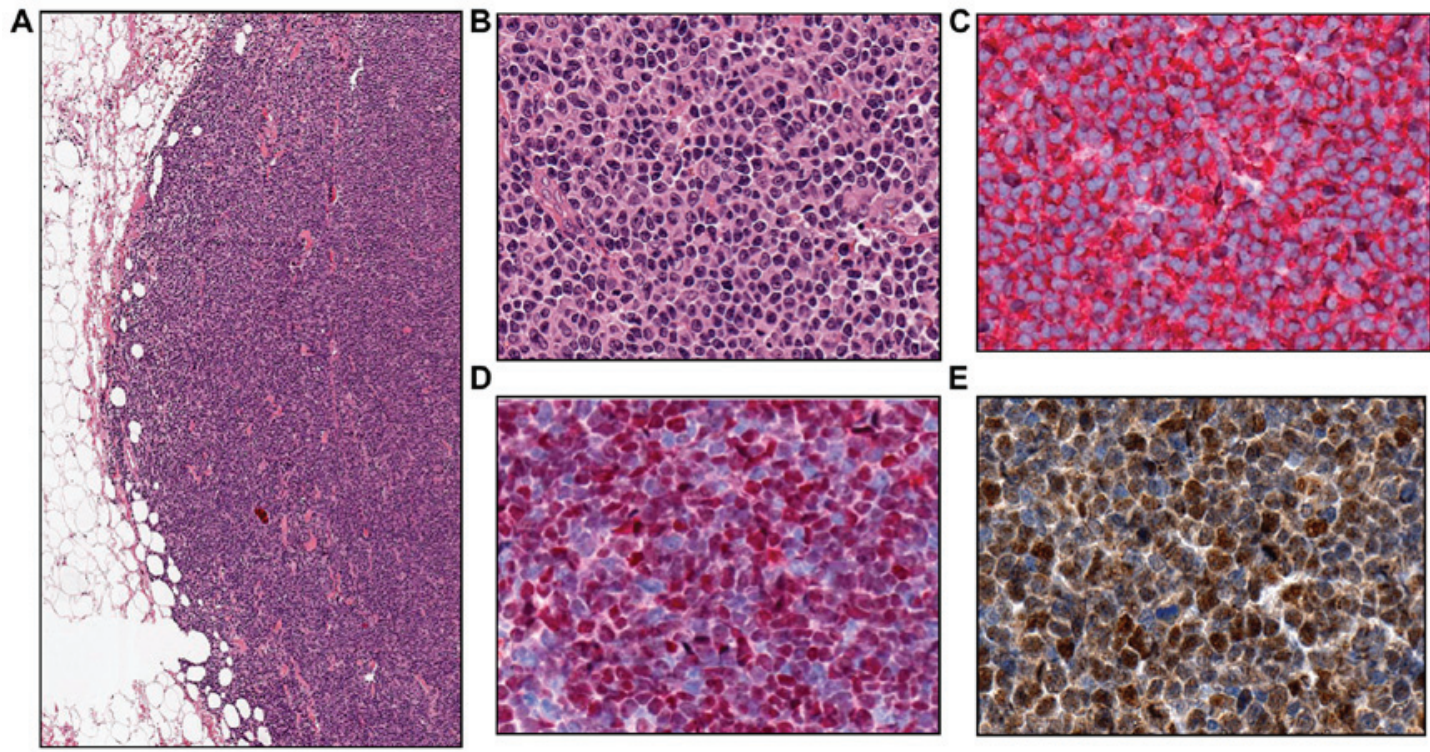

E

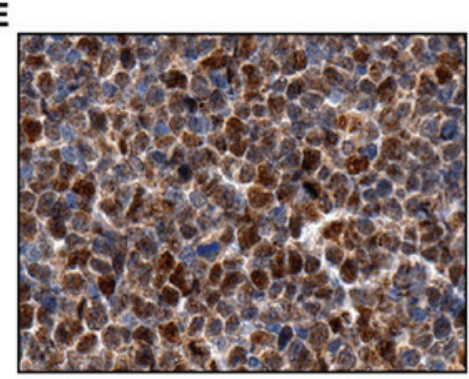

Figure 2. Histopathological findings of the subcutaneous nodule in the right infraorbital region. (A and B) Massive infiltration by medium-sized neoplastic lymphoid cells with irregular nuclei (haematoxylin and eosin staining; magnification, x40 and x200, respectively). Immunohistochemical staining revealed that the atypical lymphocytes were strongly positive for (C) CD20 (magnification, x200), (D) cyclin D1 (magnification, x200) and (E) sex-determining region Y-box 11 (magnification, x400).

axillary lymph nodes were enhanced bilaterally. Enlarged lymph nodes were also identified in the lesser curvature of the stomach, in the paraaortic and coeliac regions, and in the area between the inferior vena cava and the head of the pancreas (Fig. 3). Magnetic resonance imaging of the head revealed a $4.0 \times 4.1 \times 3.0-\mathrm{cm}$ homogeneously-enhanced epipharyngeal mass growing through the choanae into the nasal cavity, with enlarged parapharyngeal lymph nodes bilaterally. There were no cerebral pathological findings. A bone marrow biopsy revealed diffuse infiltration by neoplastic lymphoma cells.

Based on the clinicopathological and immunohistochemical findings, the diagnosis of a cutaneous variant of MCL at stage IVEB was established. Furthermore, chronic hepatitis B of unknown origin was newly diagnosed. Antiviral therapy with entecavir was initiated. The patient received six cycles of adjuvant chemotherapy with rituximab, cyclophosphamide, doxorubicin, vincristine, and prednisone (R-CHOP-14), administered once a day for 2 weeks, along with three cycles of intrathecal methotrexate as central nervous system (CNS) prophylaxis, with no associated side effects. After the initial chemotherapy treatments, stem cells were collected from the patient's bone marrow, in case of the need for relapse therapy with a peripheral blood stem cell transplant (PBSC).

After 10 weeks, the patient was restaged and found to have a complete remission (CR); she remained in CR until November, 2009, when she presented with a discrete axillary, inguinal and mesenteric nodal recurrence and bone marrow infiltration. The patient was treated with two cycles of rituximab, cisplatin, cytosine arabinoside and dexamethasone (R-DHAP) and one cycle of intrathecal methotrexate as CNS prophylaxis. Restaging by CT and bone marrow biopsy confirmed partial remission. Subsequently, the patient was consolidated with PBSC using etoposide, cytosine arabinoside and melphalane (BEAM conditioning regimen), which was associated with moderate to severe toxicity in the form of 


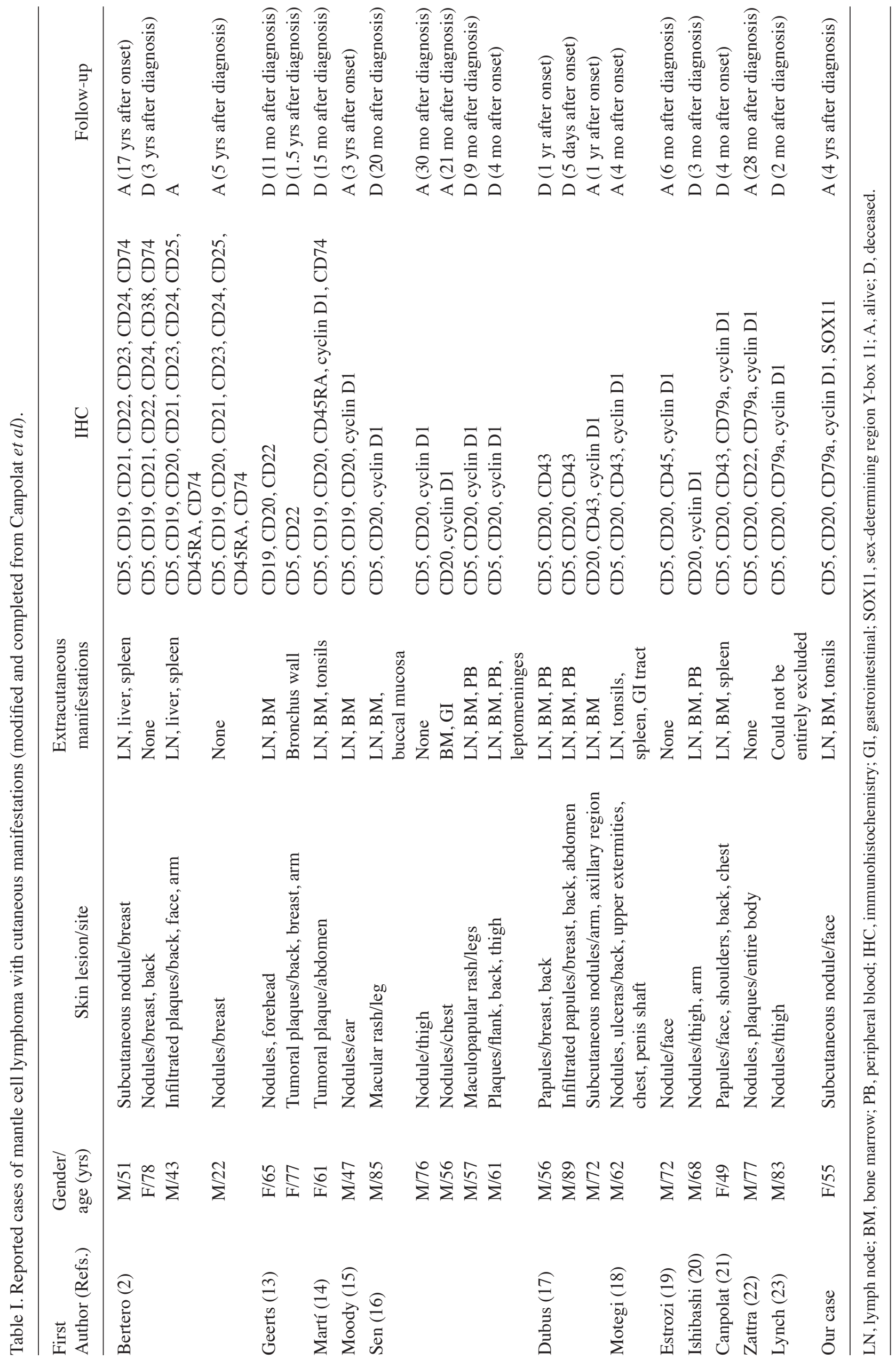




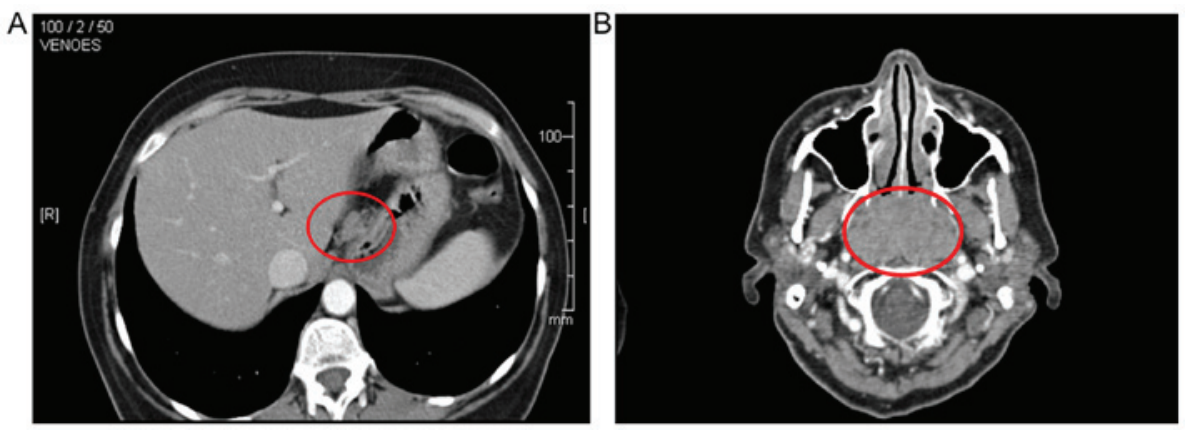

Figure 3. Computed tomography scans of (A) the abdomen, showing enlarged lymph nodes in the area of the pancreatic head and (B) the cervical region, showing a space-occupying lesion in the nasopharynx and displacement of the peripheral structures, minor perfusion centrally and missing inner linear structures (red circles)

fatigue, neutropenic fever and Clostridium difficile-positive diarrhea. Following induction of an intensive antibiotic and infusion treatment regimen, the patient's symptoms and signs of infection regressed. At present, 2 years after PBSC and 4 years after the appearance of the skin lesion, the patient is well, with no evidence of relapse.

Written informed consent was obtained from the patient for publication of this case report and any accompanying images. A copy of the written consent is available for review by the Editor of this journal.

\section{Discussion}

MCL is a B-cell lymphoma that affects older patients, with a median age of incidence at 68 years. MCL represents $\sim 6 \%$ of all NHL subtypes (3) with a male-to-female incidence ratio of 3:1 $(4,5)$. The prevalence is estimated to be $\sim 2-3$ cases per 100,000 patients per year (6). The overall median survival (OS) of MCL is 3-5 years. Adjuvant chemotherapy with the $\mathrm{R}-\mathrm{CHOP}$ regimen in patients with untreated MCL achieved an overall response rate of $96 \%(7,8)$.

MCL occurs primarily in lymph nodes and extranodal organs, including the bone marrow, spleen and gastrointestinal tract. Skin involvement occurs in 2\% of MCL cases and is associated with progressive disease (4,9). Immunophenotypically, MCL consist of $\mathrm{CD}^{-}, \mathrm{CD}^{-} 9^{-}, \mathrm{CD}_{20}{ }^{-}, \mathrm{CD}_{22}^{-}, \mathrm{CD}^{-} 5^{-}$and $\mathrm{CD}_{79 \mathrm{a}^{+}}$tumor cells that are usually negative for CD10, CD23 and BCL-6. The majority of MCLs are characterized by overexpression of cyclin $\mathrm{D} 1$, as a result of the $\mathrm{t}(11 ; 14)$ (q13;q32)/CCND1-IGH translocation (1).

SOX11 is a transcription factor that is involved in embryogenic development. Recent studies have demonstrated overexpression of SOX11 in MCL (10), but its prognostic significance remains controversial. Nygren et al found that the OS of SOX11-negative cases was lower compared with that of SOX11-positive cases (median OS: 1.5 vs. 3.2 years, respectively; $\mathrm{P}=0.014$ ) (11). Conversely, Fernandez et al found that patients with SOX11-negative tumors developed a predominantly extranodal type of MCL and were characterized by longer survival compared with SOX11-positive cases (5-year OS rate, 78 vs. $36 \%$, respectively; $\mathrm{P}=0.001$ ) (12).

Skin manifestations of MCL are rare. Thus far, detailed reports in the English literature have described only 22 patients with MCL exhibiting skin lesions. The median age at the time of diagnosis is 63.6 years (range, $22-89$ years). The most common cutaneous lesion has been described as a nodule (occurring in $56.5 \%$ of all patients), with a male-to-female ratio of 17:6. The majority of the patients $(73.9 \%)$ with this lesion also present with extracutaneous involvement, such as of the bone marrow, lymph nodes and spleen. Of the $22 \mathrm{MCL}$ patients with cutaneous manifestations identified, 12 succumbed to the disease (2,13-23). In those cases, the mean survival time from the diagnosis of cutaneous manifestations to death was 11.2 months (range, 5 days-36 months). The published cases are summarized in Table I.

We herein described a rare case of MCL with involvement of the skin in the right infraorbital region, with a detailed 4-year follow-up and review of the available literature. The patient's skin biopsy revealed that the neoplastic tumor cells exhibited the characteristic cytology of MCL and were positive for CD5, CD20, CD79a, cyclin D1 and SOX11. To the best of our knowledge, this is the first report of a case of MCL with SOX11-positive tumor cells in a skin lesion. Our patient remains alive and well, with no evidence of disease relapse. This study also highlights the need for further investigation, in order to elucidate the role of SOX11 in the pathogenesis and prognosis of MCL with cutaneous manifestations.

\section{Acknowledgements}

The authors wish to acknowledge the valuable contribution of Dr Thomas Koculak for the high-quality images.

\section{References}

1. Leonard JP, Williams ME, Goy A, Grant S, Pfreundschuh M, Rosen ST and Sweetenham JW: Mantle cell lymphoma: Biological insights and treatment advances. Clin Lymphoma Myeloma 9: 267-277, 2009.

2. Bertero M, Novelli M, Fierro MT and Bernengo MG: Mantle zone lymphoma: An immunohistologic study of skin lesions. J Am Acad Dermatol 30: 23-30, 1994.

3. Weigert O, Unterhalt M, Hiddemann $W$ and Dreyling M: Mantle cell lymphoma: State-of-the-art management and future perspective. Leuk Lymphoma 50: 1937-1950, 2009.

4. Samaha H, Dumontet C, Ketterer N, Moullet I, Thieblemont C, Bouafia F, Callet-Bauchu E, Felman P, Berger F, Salles G and Coiffier B: Mantle cell lymphoma: A retrospective study of 121 cases. Leukemia 12: 1281-1287, 1998.

5. Oinonen R, Franssila K, Teerenhovi L, Lappalainen K and Elonen E: Mantle cell lymphoma: Clinical features, treatment and prognosis of 94 patients. Eur J Cancer 34: 329-336, 1998 
6. Meusers P, Hense J and Brittinger G: Mantle cell lymphoma: Diagnostic criteria, clinical aspects and therapeutic problems Leukemia 11 (Suppl 2): S60-S64, 1997.

7. Howard OM, Gribben JG, Neuberg DS, Grossbard M, Poor C, Janicek MJ and Shipp MA: Rituximab and CHOP induction therapy for newly diagnosed mantle-cell lymphoma: Molecular complete responses are not predictive of progression-free survival. J Clin Oncol 20: 1288-1294, 2002.

8. Lenz G, Dreyling M, Hoster E, Wörmann B, Dührsen U, Metzner B, Eimermacher H, Neubauer A, Wandt $H$, Steinhauer $\mathrm{H}$, et al: Immunochemotherapy with rituximab and cyclophosphamide, doxorubicin, vincristine and prednisone significantly improves response and time to treatment failure, but not long-term outcome in patients with previously untreated mantle cell lymphoma: Results of a prospective randomized trial of the German Low Grade Lymphoma Study Group (GLSG). J Clin Oncol 23: 1984-1992, 2005.

9. Argatoff LH, Connors JM, Klasa RJ, Horsman DE and Gascoyne RD: Mantle cell lymphoma: A clinicopathologic study of 80 cases. Blood 89: 2067-2078, 1997.

10. Xu W and Li JY: SOX11 expression in mantle cell lymphoma. Leuk Lymphoma 51: 1962-1967, 2010.

11. Nygren L, Baumgartner Wennerholm S, Klimkowska M, Christensson B, Kimby E and Sander B: Prognostic role of SOX11 in a population-based cohort of mantle cell lymphoma. Blood 119: 4215-4223, 2012.

12. Fernàndez V, Salamero $O$, Espinet $B$, Solé $F$, Royo $C$, Navarro $A$ Camacho F, Beà S, Hartmann E, Amador V, et al: Genomic and gene expression profiling defines indolent forms of mantle cell lymphoma. Cancer Res 70: 1408-1418, 2010.

13. Geerts ML and Busschots AM: Mantle-cell lymphomas of the skin. Dermatol Clin 12: 409-417, 1994.

14. Martí RM, Campo E, Bosch F, Palou J and Estrach T: Cutaneous lymphocyte-associated antigen (CLA) expression in a lymphoblastoid mantle cell lymphoma presenting with skin lesions Comparison with other clinicopathologic presentations of mantle cell lymphoma. J Cutan Pathol 28: 256-264, 2001.
15. Moody BR, Bartlett NL, George DW, Price CR, Breer WA, Rothschild Y and Kraus MD: Cyclin D1 as an aid in the diagnosis of mantle cell lymphoma in skin biopsies: A case report. Am J Dermatopathol 23: 470-476, 2001.

16. Sen F, Medeiros LJ, Lu D, Jones D, Lai R, Katz R and Abruzzo LV: Mantle cell lymphoma involving skin: Cutaneous lesions may be the first manifestation of disease and tumors often have blastoid cytologic features. Am J Surg Pathol 26: 1312-1318, 2002.

17. Dubus P, Young P, Beylot-Barry M, Belaud-Rotureau MA, Courville P, Vergier B, Parrens M, Lenormand B, Joly P and Merlio JP: Value of interphase FISH for the diagnosis of $t(11: 14)$ (q13;q32) on skin lesions of mantle cell lymphoma. Am J Clin Pathol 118: 832-841, 2002.

18. Motegi S, Okada E, Nagai Y, Tamura A and Ishikawa O: Skin manifestation of mantle cell lymphoma. Eur J Dermatol 16: 435-478, 2006

19. Estrozi B, SanchesJA Jr, Varela PC and Bacchi CE: Primary cutaneous blastoid mantle cell lymphoma-case report. Am J Dermatopathol 31: 398-400, 2009.

20. Ishibashi M, Yamamoto K, Kudo S and Chen KR: Mantle cell lymphoma with skin invasion characterized by the common variant in the subcutis and blastoid transformation in the overlying dermis. Am J Dermatopathol 32: 180-182, 2010.

21. Canpolat F, Taş E, Albayrak Sönmez A, Oktay M, Eskioğlu F and Alper M: Cutaneous presentation of mantle cell lymphoma. Acta Derm Venerol 90: 548-550, 2010.

22. Zattra E, Zambello R, Marino F, Bordignon M and Alaibac M: Primary cutaneous mantle cell lymphoma. Acta Derm Venerol 91: 474-475, 2011.

23. Lynch DW, Verma R, Larson E, Geis MC and Jassim AD: Primary cutaneous mantle cell lymphoma with blastic features: report of a rare case with special reference to staging and effectiveness of chemotherapy. J Cutan Pathol 39: 449-453, 2012. 